\title{
Editorials
}

\section{The future funding of health and social care in England}

These are embarrassing times for baby boomers. As beneficiaries of the Attlee settlement, we have enjoyed affordable health care, decent housing, free higher education and a generous welfare state. Notoriously, these are blessings that could be denied the next generation. ${ }^{1}$

The NHS is facing yet another funding crisis and social care is under increasing strain. The confusing border between the two has long been a source of administrative waste and frustration for users. Patterns of ill health, life expectancy, family structures, and medical technologies have changed considerably since 1948 when Beveridge and Bevan established the current system. A King's Fund commission, chaired by the economist Kate Barker, proposes a new settlement fit for today's circumstances. ${ }^{2}$

An interim report used five criteria to assess future options: equity, transparency, efficiency, the split between collective and individual responsibility, and affordability. ${ }^{3}$ The evidence suggests that the present arrangements fail on all of these criteria.

\section{SYSTEMIC FAILINGS}

The contrast between a health service free at the point of use and a social care service that is means tested and publicly funded only for those with heavy needs, means that the type of ailment you have determines the financial support you receive. Compare the personal cost consequences to our patients of developing cancer or dementia. The outcome of this 'lottery' is inequitable; similar needs do not receive equal treatment.

The current lack of funding for social care is little understood by the public; greater transparency is badly needed. Sir Andrew Dilnot's proposed reforms to the funding of social care, due to be implemented in 2017. are a step forward. ${ }^{4}$ The higher threshold for the means test will allow people to keep E118 000 of assets, rather than the current E23 250, and still receive local authority funding. Above that, however, those who can will still have to meet the first $€ 72000$ of the cost of their social care. ${ }^{5}$

Efficiency is hampered by a lack of organisational integration, health is run by the NHS and social care by local authorities, with the two commissioned separately. The price of this failing is well illustrated by some 3000 hospital beds occupied each day by people needing social care funding

\section{"The outcome of the present lottery is inequitable. similar needs do not receive equal treatment.}

or assessments. If anything, in recent years care has become more fragmented despite numerous initiatives to promote integration. The ill-fated $€ 3.8 \mathrm{bn}$ Better Care Fund is a further example of what Ben Ramalingam in another context calls 'best-practicitis': the short-term, localised modelling of technical fixes that don't work. ${ }^{6}$

While the NHS is often perceived as monolithic and unchanging, there have been a number of shifts in the boundary between public and private funding in the post-war period. In general, these have restricted free access to social care and increased private payment for health care. Large amounts of Continuing Healthcare have been moved out of the NHS. More social care is now provided by unpaid carers.

\section{UNIFICATION IS POSSIBLE}

The commission proposes moving towards one ring-fenced budget for health and social care, with a single commissioner and within which entitlements are much more closely aligned. Bringing the Attendance Allowance into this budget would create a more graduated pathway of support. The key issue is that of affordability.

Many believe that the health costs of the rising number of older people are simply unaffordable. In fact, it is largely advances in medical knowledge and technology that have raised costs in the health service. Ageing itself is less significant, with healthcare costs still concentrated in the last 18 months of life. And while there is a worry about old age dependency (that is, too many old people compared to workers) the proposed rises in pension age and greater participation of older people in work are changing this ratio favourably. Spijker and Maclnnes, have shown that the 'real' old age dependency ratio is lower than previously predicted as older people are increasingly 'younger' than previous cohorts. ${ }^{\text {? }}$

Furthermore, all pensioners are no longer poor pensioners. According to the Institute for Fiscal Studies (IFS), median pensioner incomes are now similar to those of the working-age population. Thirty years ago, more than $40 \%$ of pensioners were in the bottom fifth of the income distribution as compared with $10 \%$ today. ${ }^{8}$

Currently, more than one-quarter of GDP is spent on pensions, health, and social care; items chiefly consumed by older people. Recent estimates from the Office for Budget Responsibility suggest that in 2062-2063, health, social care, and pensions could together absorb almost $50 \%$ of public spending and almost $20 \%$ of GDP even on the basis of current entitlements. ${ }^{9}$ Health costs will continue to rise but, as income levels rise, people choose to spend more on health care labove a certain level of spend, health care is what economists call a 'luxury good', not a 'need').

The commission's figures imply that health and social care are not, currently or in the foreseeable future, either unaffordable or unsustainable. Spending on them, as the economy grows, is a matter of political will and individual choice, expressed both by how much people choose to spend themselves, and by which politicians they choose to elect.

Regarding entitlements, the broad choice is whether to align social care more closely with health, or the other way around. Social care could be aligned with health by making 


\section{Box 1. Possibilities for paying for the new settlement}

- Productivity improvements

- Revamped prescription charge

- Better targeting of winter fuel payments and TV licences

- Means testing accommodation costs for Continuing Healthcare

- Ending $\mathrm{NI}$ exemptions for pension age workers

- 1p increase in NI for over 40-year-olds

- Wealth and asset taxes, for example revisions to inheritance and property taxation

more of the most acute end of social care free at the point of use; for example, care for advanced dementia, Parkinson's disease, or end-of-life care.

Health care could be aligned more closely with social care by applying the Dilnot principles to the NHS. Individuals would be covered for extreme expenditure but they would pay an appreciable amount in contributions for health as well as for social care. An annual cap for a range of charges could, for example, be set at £500 or £1000. Depending on exemptions, that could raise billions of pounds in additional funding. The Dilnot reforms to social care were expected to generate a stronger insurance market to cover costs up to the cap; charges for health could do the same. However, this approach would be administratively complex and involve extending existing charges and/or introducing new ones.

These two approaches are not mutually exclusive but to move in the directions the commission suggests will require some combination of higher taxation, new charges, or cuts in other areas of public spending.

Effective change is going to require more than better integration and improved productivity.

\section{DIFFICULT CHOICES}

A new settlement needs to provide better value for money but its costing is not straightforward. Barker proposes making critical and substantial care needs free at the point of use for older people in the first instance. ${ }^{2}$ This would cost nearly $€ 3$ billion initially and $€ 14$ billion by 2025; some 5 billion more than currently projected expenditure.

Spending on social care is inevitably going to rise whether it is funded from the public purse or privately by those unlucky individuals with high needs and their families. However, as the economy grows, it should be possible for health and social care to take a larger share of a much larger cake. More generous provision would raise expenditure on combined care to between $11 \%$ and $12 \%$ of GDP by 2025 . This compares with the $11.2 \%$ spent by France and $11.9 \%$ spent by the Netherlands in 2010 on health care alone. ${ }^{10}$

The core of the final report examines how the settlement could be paid for (Box 1).2 Most readers will be relieved that the commission did not find in favour of introducing new charges for health care, for example, for GP visits or outpatient attendances. The sums raised would be relatively small and such charges could adversely impact on the health of the poor. Hypothecated taxes are also rejected.

Not unreasonably, 'as a matter of equity and inter-generational fairness', today's older people are targeted for the greatest contributions. They are both better off than their predecessors and will be the first beneficiaries of any new settlement. Scaling back existing benefits and ending exemptions from National Insurance (NI) contributions when people work past pension age could raise $€ 2$ billion. A revamped prescription charge of $€ 2.50$ without exemptions ('the price for a posh coffee') could raise an additional $€ 1$ billion. Full implementation of their proposals will require new wealth and asset taxes, for (yes, you've guessed) scrapping those taxfree pension lump sums.

The proposed reforms would necessarily have to be phased in over the coming decade, but the report sets a direction of travel. The notion that health and wellbeing boards could evolve into the single commissioners at a local level will raise eyebrows. That the boards 'would need strengthening' is a felicitous understatement.

\section{CAN WE AFFORD TO DELAY?}

Will a newly-elected government wish to embark on such fundamental reforms? The electoral risks are considerable. Not all pundits will feel as optimistic about the economic projections presented here and some of these proposals will be unpopular. Short-sighted politicians, already facing financial shortfalls in both systems, will be tempted to kick this report into the long grass.

Unsurprisingly, the response of the main political parties has thus far been muted. However, no government can indefinitely ignore the hard choices needed to prevent a decline in England's health and social care. Squeezing the grey vote may be perilous, but perhaps we berated baby boomers can yet exonerate ourselves.

\section{ADDRESS FOR CORRESPONDENCE}

Stephen Gillam

Department of Public Health \& Primary Care, Institute of Public Health, University of Cambridge, Robinson Way, Cambridge CB2 2SR, UK.

\section{E-mail:sjg67amedschl.cam.ac.uk}

\section{Stephen Gillam,}

GP, Lea Vale Medical Group, Luton; Consultant in Public Health, Institute of Public Health, University of Cambridge, Cambridge, UK.

\section{Provenance}

Commissioned; not externally peer reviewed.

DOI: 10.3399/bjgp14X681673

\section{REFERENCES}

1. Beckett F. What did the baby boomers ever do for us? London: Biteback, 2010.

2. Commission on the Future of Health and Social Care in England. A new settlement for health and social care. Final report. London: The King's Fund, September, 2014. mww.kingsfund. org.uk/projects/commission-future-healthand-social-care-england laccessed 3 Sep 2014).

3. Commission on the Future of Health and Social Care in England. A new settlement for health and social care: Interim report. London: The King's Fund, April 2014.

4. Gillam S. Funding for social care - the continuing conundrum. Br J Gen Pract 2011; DOI: 10.3399/bjgp11X601226.

5. Commission on Funding of Care and Support Dilnot A. Fairer care funding. London: TSO, 2011.

6. Ramalingam B. Aid on the edge of chaos rethinking international co-operation in a complex world. Oxford: Oxford University Press, 2014.

7. Spijker J, Maclnnes J. Population ageing: the time bomb that isn't. BMJ 2013: 347: $\$ 6598$

8. Johnson P. Pensioner incomes in the UK. Presentation to first CEPAR annual conference. Institute for Fiscal Studies, 2013. www.ifs.org. uk/conferences/pensioner_incomesUK_pj2013. pdf (accessed 3 Sep 2014).

9. Office for Budget Responsibility. Fiscal sustainability report, July 2013. London: OBR, 2013. http://budgetresponsibility.org.uk/fiscalsustainability-report-july-2013/ laccessed 12 Sep 2014).

10. Organisation for Economic Co-operation and Development (2014). OECD health statistics 2014: frequently requested data. Paris: OECD. unw.oecd.org/health/health-systems/oecdhealth-statistics-2014-frequently-requesteddata.htm (accessed 12 Sep 2014). 